\title{
Estudo Bibliométrico sobre Organismos Vegetais Geneticamente Modificados
}

${ }^{1}$ Felipe Donizetti Carvalho, ${ }^{1}$ Heloisa Oliveira dos Santos, ${ }^{1}$ Edila Vilela de Resende

Von Pinho, ${ }^{1}$ Carla Massimo Caldeira, ${ }^{1}$ Maria Laene Moreira de Carvalho

${ }^{1}$ Universidade federal de Lavras, UFLA - Av. Doutor Sylvio Menicucci, 1001 - Kennedy, Caixa Postal 3037, 37200-000

Lavras, MG, Brasil. E-mail: lip.uf@hotmail.com; heloisasantos@dag.ufla.br; edila@dag.ufla.br; carlaufla@yahoo.com.br; mlaenemc@dag.ufla.br

ISSN 2448-0479

Resumo: Este artigo apresenta os resultados de uma pesquisa sobre os estudos realizados no mundo sobre o tema "Transgênicos" publicados entre os anos de 1998 e 2014 nos periódicos Pesquisa Agropecuária Brasileira, Journal Biotechnology, Euphytica, Journal of Agronomy and Crop Science, Crop Protection, Crop Science, Biotecnologic Review, Seed Science Research, Ciência e Agrotecnologia, Genetics and Molecular Research. Para atingir esse objetivo foram analisados os seguintes aspectos: a) o panorama global dos artigos; b) identificar as revistas com maior número de publicações, c) a quantidade de publicaçôes por seguimentos: Algodão, Soja, Milho, Resistência a Insetos, Tolerância a Herbicidas e Artigos de Revisão sobre o tema d) identificar os anos mais produtivos e a tendência de publicação ao longo do tempo; e) identificar os países que mais publicam $\mathrm{f}$ ) identificar as palavras-chave mais recorrentes nos artigos levantados, g) quantidade de autores por artigos. Foram estudados 138 artigos, e os dados foram analisados por meio de estatística descritiva e análises bibliométrica. De acordo com os resultados, a revista Crop Protection foi a que mais publicou artigos sobre transgênicos. Estados Unidos é o país que lidera o ranking de publicaçóes; a cultura do algodáo foi o segmento mais estudado, e como consequência a palavra Cotton foi a mais recorrente dentre as palavras chave. Os artigos são em sua maioria escritos por seis ou mais autores.
Palavras-chave - OGM. Grandes culturas. Proteçấo de plantas.

\begin{abstract}
This article presents the results of a survey of studies in the world on "Transgenic" published between the years 1998 and 2014 in the periodics Pesquisa Agropecuária Brasileira, Journal Biotechnology, Euphytica, Journal of Agronomy and Crop Science, Crop Protection, Crop Science, Biotecnologic Review, Seed Science Research, Ciência e Agrotecnologia, Genetics and Molecular Research. To achieve this goal the following aspects were analyzed: a) the overall picture of the articles; $b$ ) identify the magazines with the largest number of publications, c) the number of publications by segments, Cotton, Soybeans, Corn, resistance to insects, tolerance to herbicides and review articles on the topic d) identify the most productive years and publishing the trend over time; e) identify the countries that publish $\mathrm{f}$ ) identify the most frequent keywords in articles raised, g) the number of authors for articles. Data were analyzed using descriptive statistics, bibliometric analyzes, in total were selected 138 articles, the main results show us that the Crop Protection journal was the most published articles on GM; the United States is the country that leads the ranking publications; cotton was the most studied segment, and as a result the words cotton was the most frequent among the keywords, the articles are mostly written by six or more authors.
\end{abstract}


Keywords - GMO. Field crops. Plant protection.

Recebido em: 21 de março de 2016.

Aprovado em: 17 de maio de 2016.

\section{INTRODUÇÁO}

A população mundial é de 7,2 bilhôes de pessoas e estima-se que chegará a 9,6 bilhóes em 2050, segundo um relatório da Organização das Nações Unidas (ONU) (2015) que prevê que o crescimento será principalmente nos países em desenvolvimento. Diante disto um dos grandes desafios para os próximos anos é produzir alimentos com sustentabilidade para atender esta demanda.

Diante deste contexto da produção mundial de alimentos, o Brasil ocupa uma posição de destaque. O país é um dos principais exportadores de produtos agropecuários do mundo, estando entre os maiores produtores de açúcar, suco de laranja, café, além de ser o líder na exportação de soja, tabaco, etanol, carne bovina e aves (BRASIL, 2015). No Brasil, o agronegócio é responsável por cerca $14 \%$ do Produto Interno Bruto (PIB) no país, com destaque para as atividades voltadas ao mercado externo e para o crescimento da produção agrícola no desempenho positivo da renda do agronegócio (CENTRO DE ESTUDOS AVANÇADOS EM ECONOMIA APLICADA, 2015).

O avanço do agronegócio no país se deu a partir dos anos 70 com a criaçáo da Empresa Brasileira de Pesquisa Agropecuária (EMBRAPA), e dos intensos trabalhos de pesquisa das instituições de ensino, pesquisa e extensão. Estes avanços possibilitaram a inserçấo da agricultura no cerrado brasileiro, uma das maiores regióes produtoras de grãos do país. $\mathrm{O}$ agronegócio brasileiro desponta como um campo promissor para as pesquisas científicas, uma vez que é notório o crescimento acelerado advindo de uma demanda garantida de mercado. (SOUZA et al., 2012).

O agronegócio brasileiro tende a crescer a cada ano, sendo que na safra 2014/2015, levando em consideração as áreas cultivadas de grãos com as culturas de verão e segunda safra, ocupou uma área de 56,85 milhóes de hectares, com um incremento de $6,1 \%$ na área cultivada quando comparado à safra 2013/14, representando um aumento de 3,29 milhóes de hectares (COMPANHIA NACIONAL DE ABASTECIMENTO, 2014). Entretanto mais importante que o aumento da área de produção de alimento é o aumento da produtividade, visando uma agricul- tura sustentável. Esse aumento na produtividade no campo muito se deve ao uso da transgenia que possibilitou uma maior facilidade de produçáo para os agricultores. No Brasil a transgenia contribuiu para consolidar o agronegócio do país e potencializar a produçáo de grãos, ao sucesso dos benefícios obtidos com a produção de plantas transgênicas resistentes a doenças e insetos, a redução no uso de defensivos e o aumento da produção (CARRER et al., 2010).

Questóes sociais e ambientais foram minimizadas por essa tecnologia uma vez que, um dos grandes problemas na produção agrícola no Brasil era a falta de mão de obra que inviabilizava a produção em grande escala, e o uso intensificado de defensivos químicos para controlar os níveis de ataque de pragas e doenças. Com a utilização da transgenia foi possível observar uma redução significativa do uso de água e de herbicidas na produção (MENEGATTI; BARROS, 2007), tornando a agricultura mais sustentável.

Os organismos geneticamente modificados (OGM) entraram no mercado de forma expressiva na agricultura na década de 90, sendo uma tecnologia recente que nos estimula a usá-la de forma correta. A garantia de longevidade de um evento transgênico depende muito da forma como este é utilizado pelos produtores. $\mathrm{O}$ uso de áreas de refúgio, rotação de cultura, rotação de produtos químicos são algumas estratégias para garantir a durabilidade de um evento (LANDGRAF, 2014).

A adoção de biotecnologia agrícola no Brasil vem crescendo a cada ano. Segundo dados da fundação Clive James, na safra 2014 foram plantados 42,4 milhôes de hectares com soja, milho e algodão transgênico, sendo o segundo país em área plantada com materiais geneticamente modificados. Quando se fala em adoção da biotecnologia por eventos, a tolerância a herbicidas lidera o mercado de transgênicos seguida dos tratamentos combinados resistência a insetos e tolerância a herbicidas (RI e TH respectivamente) e por fim a resistência a insetos de forma isolada (JAMES, 2014).

Segundo Borém e Fritsche-Neto (2014) estudos que envolvem engenharia genética são de extrema importância para a sociedade uma vez que trazem inúmeras vantagens a exemplo de incremento da produção com consequente redução dos custos e diferentes alternativas para a exportação de produtos agrícolas. Além de possibilitar um maior controle ambiental com redução da adoção de defensivos químicos e aumento da variabilidade genética pela inserção de genes exógenos no genoma principal, dentre outras. 
Diante disso no presente trabalho buscou-se fazer uma revisão sistemática de literatura com intuito de relatar o que está sendo publicado em 10 das principais revistas que abordam o tema transgenia.

\section{METODOLOGIA}

Foi usada como amostra intencional dez periódicos (Tabela 1) com classificação no sistema Qualis e que possuem acesso livre na internet. Foram consultadas todas as ediçôes e todas as publicaçóes disponíveis no período de janeiro de 1998 até as edições de outubro de 2014.

Tabela 1. Relação dos periódicos analisados e sua classificação Qualis Capes.

\begin{tabular}{|c|c|}
\hline Nome do Periódico & $\begin{array}{c}\text { Classificaçáo } \\
\text { Qualis Capes }\end{array}$ \\
\hline Pesquisa Agropecuária Brasileira & $\mathrm{B} 1$ \\
Journal Biotechnology & $\mathrm{A} 1$ \\
Euphytica & $\mathrm{A} 2$ \\
Journal of Agronomy and Crop & $\mathrm{A} 2$ \\
Science & \\
Crop Protection & $\mathrm{B} 1$ \\
Crop Science & $\mathrm{A} 1$ \\
Biotecnologic Review & $\mathrm{A} 2$ \\
Seed Science Research & $\mathrm{A} 2$ \\
Ciência e Agrotecnologia & $\mathrm{A} 2$ \\
Genetics and Molecular Research & $\mathrm{A} 1$ \\
\hline
\end{tabular}

A coleta de dados foi efetuada pelo levantamento das publicaçóes destes periódicos, visita aos sítios ativos na internet e verificação de suas relações entre: título, palavras-chave, resumo sobre o tema organismos geneticamente modificados e quebra de resistência dos organismos alvos da tecnologia dentre as culturas soja, milho, algodão.

As informaçōes coletadas foram trabalhadas usando planilhas do Microsoft Excel mediante procedimentos analíticos em todo o transcorrer da pesquisa, desde o momento da ocorrência do objetivo selecionado na pesquisa até as consideraçôes finais. Ressalta-se ainda que a tarefa de analisar os dados implicou, num primeiro momento, na organizaçáo de todo o material, dividindo-o em partes, relacionando essas partes e procurando identificar tendências ou padrôes relevantes.

Foram analisados os seguintes aspectos nos artigos encontrados: classificação dos artigos por seguimentos, palavras-chave mais recorrentes nos artigos, distribuição de número de autores por artigo e distribuiçẫo de autores por países.

\section{RESULTADOS E DISCUSSÃO}

Foram identificados 138 artigos com o tema transgênicos nos dez periódicos analisados durante o periodo de 1998 e 2014.

No gráfico 1, observa-se que o ano de 2007 teve o maior número de publicaçóes sobre transgenia dentre as revistas analisadas, o qual apresentou 17 artigos. Esse aumento nos estudos sobre transgênicos se justifica pela aprovação da lei de Biosseguraça em 2005, Lei 11.105, que passou a estabelecer normas de segurança e mecanismos de fiscaliação de OGM, legalizando a situação dos transgênicos no país. Antes de 2005, a média de publicaçáo de artigos com o

\section{NÚMERO DE ARTIGOS/ANO}

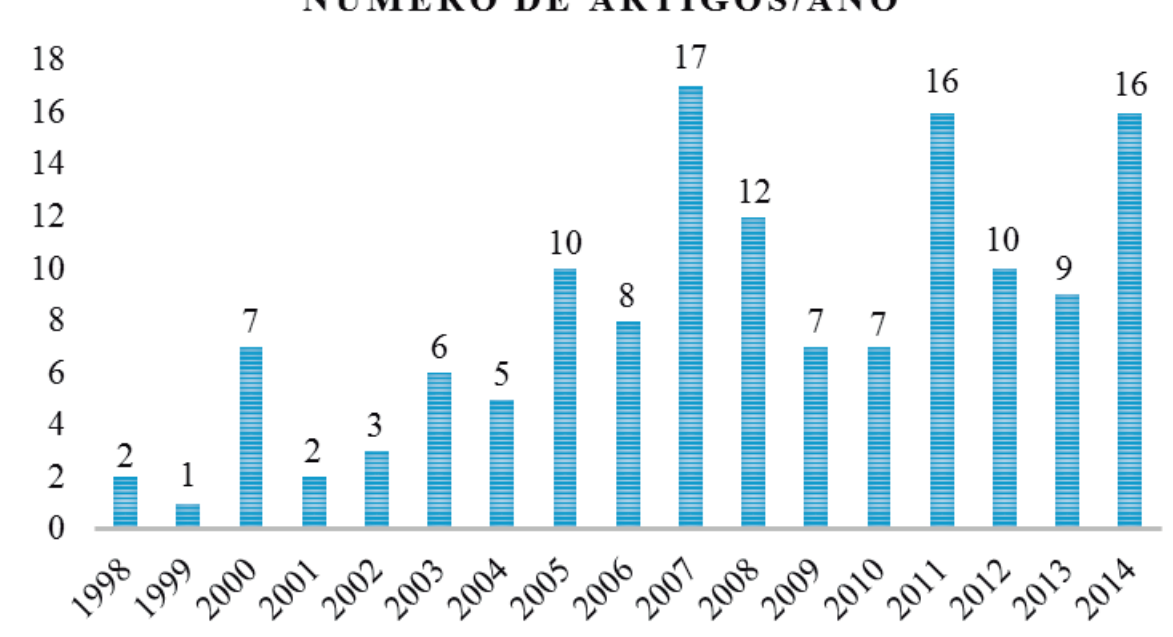

Gráfico 1. Relação entre o número de artigos publicados por ano, em 10 revistas que abordam o tema transgenia. 
tema foi de 3,71 artigos/ano enquanto que após 2005 foi de 11,2 artigos/ano, um aumento de aproximadamente $200 \%$ nas publicaçóes. Verificou-se uma grande variedade de temática entre os artigos, mostrando que dentre o tema transgenia há uma ampla gama de assuntos como alimentação, resistência a herbicidas, resistência a insetos, fluxo gênico, entre outros.

Dentre as dez revistas, foram analisadas 1295 ediçôes com um número de 138 artigos relacionados ao tema transgênicos (Tabela 2). As revistas que tiveram maior número de artigos publicados relacionados ao tema da pesquisa foram: Crop Protection, Pesquisa Agropecuária Brasileira (PAB), e Crop Science respectivamente, somando um total de 111 artigos. Ressalta-se que a revista Ciência e Agrotecnologia e Seed Science Research não apresentaram, em nenhuma de suas edições, artigo sobre a área de estudo.

Tabela 2. Relação do número de artigos sobre transgênicos e número de ediçôes analisadas nas Revistas pesquisadas no estudo.

\begin{tabular}{|c|c|c|}
\hline Nome do Periódico & $\begin{array}{c}\text { Número de } \\
\text { Artigos } \\
\text { Sobre } \\
\text { Transgênicos }\end{array}$ & $\begin{array}{c}\text { Número de } \\
\text { Ediçóes } \\
\text { Analisadas }\end{array}$ \\
\hline $\begin{array}{c}\text { Pesquisa Agropecuária } \\
\text { Brasileira }\end{array}$ & 24 & 190 \\
Journal Biotechnology & 5 & 190 \\
Euphytica & 11 & 285 \\
Journal of Agronomy & 3 & 124 \\
and Crop Science & 18 & 190 \\
Crop Protection & 69 & 95 \\
Crop Science & 18 & 11 \\
Biotecnologic Review & 3 & 63 \\
Seed Science Research & 0 & 95 \\
Ciência e Agrotecno- & 0 & $\mathbf{1 2 9 5}$ \\
logia & 5 & $\mathbf{1 3 8}$ \\
Genetics and Molecu- & 52 \\
lar Research & & \\
\hline TOTAL & & \\
\hline
\end{tabular}

Separou-se os artigos por segmentos de acordo com as culturas Soja, Milho, Algodão, tipo de evento como tolerância a herbicida e resistência a insetos e também por artigos de revisão de literatura (Tabela 3). Ressalta-se ainda que os artigos que continham em suas especificaçóes tanto o evento quanto a cultura, foram direcionados para a cultura, ou seja, artigos que relatavam os eventos em outras culturas, que não as citadas, foram incorporados à classe do evento.

Observa-se em relação às culturas estudadas, um número maior de publicaçóes tendo o algodáo como a espécie de maior interesse, sendo 29\% dos 138 artigos analisados (Tabela 3).

É valido ressaltar ainda que dentre os materiais genéticos modificados presentes no mercado nacional, a semente de algodão é a de maior custo para o produtor. Logo, é justificável o grande numero de trabalhos relacionados a esta cultura. Em seguida aparece o Milho e a Soja com 34 e 31 publicaçôes respectivamente.

Dentre o tipo de evento destacou-se com 17 artigos os eventos relacionados com resistência a insetos. A tecnologia de tolerância a herbicidas ficou com 11 publicaçôes e por fim 5 artigos de revisão.

Observa-se, na tabela 4 , as palavras-chave mais relevantes tratadas nos artigos analisados referente a transgênicos. Cotton foi o assunto mais referenciado nas palavras-chave da pesquisa em 5 artigos, seguida de Resistance encontrada em quatro artigos. Diante do exposto, esta informação confirma mais uma vez a importância da cultura do algodáo. Um dos fatores que limita a utilização de algodão transgêncio no país são as zonas de exclusão, ou seja, áreas onde é proibido plantar algodão transênico. Essa medida visa proteger as áreas com cultivo de espécies tradicionais e naturalizadas de algodão, além de assegurar que a inovação não altere a estrutura produtiva existente (BRASIL, 2005).

Anticarsia gemmatalis (Lagarta da soja), citada como plavra-chave em 3 artigos, se destaca como uma das mais importantes pragas na cultura na soja. É uma lagarta desfolhadora que acarreta maiores prejuízos para a cultura (BORTOLI et al. 2012), por sua abundância e ocorrência frequente em todas as regióes do país onde a soja é cultivada. Inicialmente as lagartas mais novas raspam as folhas, produzindo pequenos danos, mas à medida que crescem, ficam mais vorazes, destruindo as folhas e até hastes mais finas

Tabela 3. Classificação, em porcentagem, dos artigos por seguimentos de tecnologia.

\begin{tabular}{|l|c|c|c|c|c|c|}
\hline \multirow{2}{*}{ Tipo de publicaçáo } & \multicolumn{3}{|c|}{ Culturas } & \multicolumn{2}{c|}{ Tipo de Tecnologia } & \multirow{2}{*}{$\begin{array}{c}\text { Artigos } \\
\text { de Revisáo }\end{array}$} \\
\cline { 2 - 7 } & Soja & Milho & Algodão & Tolerância a Herbicidas & Resistência a Insetos & 4 \\
\hline Número de Artigos & 22 & 25 & 29 & 8 & 12 & 4 \\
\hline
\end{tabular}


(MOSCARDI et al., 2012). Diante disto, pesquisas que visam desenvolver materiais com resistência a esta praga se torna foco de vários estudos, como observado em artigos encontrados neste levantamento.

Dentre todas as publicaçóes observou-se 343 palavras-chave o que nos revela que os temas pesquisados são muito diversificados, contudo não fogem ao tema central correspondente a transgenia. As publicaçôes são voltadas para as culturas com eventos liberados no Brasil, como soja, milho, algodáo, feijão, e mais recentemente eucalipto.

Tabela 4. Palavras-chave mais recorrentes nos artigos selecionados em 10 revistas que abordam o tema transgenia.

\begin{tabular}{|c|c|}
\hline Palavras-chave & $\mathbf{N}^{\circ}$ de artigos \\
\hline Cotton & 5 \\
Resistance & 4 \\
Transgenic crop & 3 \\
Transgenic maize & 3 \\
Zea mays & 3 \\
Non-Target Effects & 3 \\
Helicoverpa armigera & 3 \\
Gossypium hirsutum & 3 \\
Glyphosate & 3 \\
Controle Biológico & 3 \\
Anticarsia gemmatalis & 3 \\
(Lagarta da Soja) & \\
\hline
\end{tabular}

Em relação à quantidade de autores por artigo observa-se que a maioria são publicados com seis ou mais autores (Tabela 5). É valido ressaltar que pesquisas muitas das vezes são desenvolvidas por grupos de pesquisadores, o que justifica o maior número autores nos trabalhos.

Tabela 5. Distribuição de número de autores por artigo.

\begin{tabular}{|c|c|}
\hline Autores & $\mathbf{N}^{\circ}$ de Artigos \\
\hline 1 & 3 \\
2 & 22 \\
3 & 27 \\
4 & 26 \\
5 & 17 \\
$6+$ & 43 \\
\hline Total & $\mathbf{1 3 8}$ \\
\hline
\end{tabular}

Na tabela 6 observa-se os dados referentes a classificação regional dos autores, de acordo com o local de seu vínculo institucional. Os Estados Unidos estão em primeiro lugar em números de publicaçôes seguido do Brasil, China e Índia respectivamente. Entretanto pode-se observar um grande número de países envolvidos em pesquisas sobre transgênicos pelo mundo o que implica que a tecnologia está sendo implantada em todos os continentes e em sua maioria por países em desenvolvimento.

Ressalta-se que houve artigos escritos por pesquisadores de países distintos e estes foram computados em um único artigo, por isso o número maior de autores em relação ao número de artigos.

Tabela 6. Número de artigos publicados levando em consideração a distribuição dos autores por países.

\begin{tabular}{|c|c|c|c|}
\hline País & $\begin{array}{c}\mathrm{N}^{\circ} \\
\text { Publica- } \\
\text { çóes }\end{array}$ & País & $\begin{array}{c}\mathrm{N}^{\circ} \\
\text { Publica- } \\
\text { çóes }\end{array}$ \\
\hline Estados Unidos & 49 & Japão & 1 \\
\hline Brasil & 38 & Camarões & 1 \\
\hline China & 16 & Nigéria & 1 \\
\hline Índia & 10 & Itália & 1 \\
\hline África do Sul & 7 & Kenya & 1 \\
\hline França & 5 & Tailândia & 1 \\
\hline Canadá & 5 & $\begin{array}{l}\text { República } \\
\text { Tcheca }\end{array}$ & 1 \\
\hline Argentina & 5 & Iran & 1 \\
\hline Austrália & 4 & Burkina Faso & 1 \\
\hline Alemanha & 4 & $\begin{array}{l}\text { Moçambi- } \\
\text { que }\end{array}$ & 1 \\
\hline Turquia & 2 & Filipinas & 1 \\
\hline Paquistão & 2 & Zimbawe & 1 \\
\hline Espanha & 2 & Grécia & 1 \\
\hline Israel & 2 & Noruega & 1 \\
\hline Reino Unido & 2 & Suíça & 1 \\
\hline Romênia & 1 & Chile & 1 \\
\hline Hungria & 1 & Cnile & 1 \\
\hline \multicolumn{2}{|c|}{$\begin{array}{c}\text { Total de artigos } \\
\text { publicados }\end{array}$} & & 171 \\
\hline
\end{tabular}

A exceção dos trabalhos dos EUA, é possível observar um domínio nas publicações de trabalhos com origem em países em desenvolvimento a exemplo de Brasil, China e Índia. Tal fato esta relacionado ao incentivo dado aos pesquisadores desses países nos últimos anos, o que reflete diretamente no número de artigos publicados em revistas com alto fator de impacto. No entanto, grande parte desses trabalhos 
ainda são publicados em revista com baixo fator de impacto e muitas vezes em língua nativa.

Meneghini e Packer (2006) afirmam que a decisão de países em desenvolvimento em adotar a estratégia de aumentar a publicação de periódicos nacionais tem a ver com vários fatores, destacando a dificuldade em superar barreiras para publicação em periódicos internacionais. Essa dificuldade tem sido largamente discutida com respeito às suas causas e, certamente, algumas delas são facilmente identificáveis: a qualidade média inferior da ciência produzida em países em desenvolvimento, proficiência pobre no inglês escrito, e, embora não como causa maior, preconceito dos editores internacionais ao examinar artigos de países em desenvolvimento.

Como consequência, a forte atividade científica em países em desenvolvimento, nas últimas três décadas, forçou vários grupos de pesquisadores a lançar um grande número de periódicos para dar vazão a essa massa de resultados por meio de publicações.

\section{CONSIDERAÇÓES FINAIS}

Neste estudo, de acordo com o objetivo proposto, foi analisado o perfil dos artigos sobre transgênicos, publicados em periódicos Capes, no período de 1998 a 2014.

Com base nos dados analisados foi possível observar que a transgenia tem favorecido o desenvolvimento da agricultura mundial pelo aumento de produtividade e consequente redução dos custos de produção, diminuição de defensivos utilizados na produção, aumento da variabilidade genética, melhoria da qualidade dos produtos agrícolas e segue como tendência para diminuir a fome no mundo.

Estudos bibliométricos na área de transgenia proporciona ao pesquisador da área de biotecnologia identificar com rapidez os periódicos, os autores, os países que divulgam temas relacionados com a pesquisa.

Foram encontrados 138 artigos relacionados à transgenia nos 1295 volumes de periódicos dentre as dez revistas analisadas, com destaque para a revista Crop Protection onde foram identificados o maior número de artigos sobre esta temática. Constatou-se que os Estados Unidos lideram com o maior número de publicaçóes e a cultura do algodão foi a mais estudada. Como consequência a palavra Cotton foi a que mais apareceu dentre as palavras chaves dos artigos. Foi possível observar também que a maioria dos ar- tigos são publicados por seis ou mais pesquisadores, ressaltando a importância de se trabalhar em conjunto para se obter resultados mais satisfatórios.

Houve um avançado significativo nas pesquisas sobre o tema transgenia, a evolução da quantidade de artigos publicados ao longo dos anos e o grande número de palavras chave encontradas nos artigos corrobora com esta afirmativa.

Com a não utilizaçấo de áreas de refúgio pelos produtores, as tecnologias já existentes estão perdendo sua eficácia e gerando resistência de insetos e das plantas daninhas inerentes à lavoura, o que leva a um número maior de aplicações nas culturas e por consequência aumento do custo de produção, resultando numa menor adoção de sementes transgênicas nas últimas safras.

No entanto, é válido ressaltar que as empresas produtoras de sementes têm buscado novas tecnologias com diferentes aplicaçốes, e não somente materiais resistentes a insetos e/ou tolerantes a herbicidas. Como é visto dentro do portifólio da empresa Monsanto, que tem investido significativamente em materiais de soja para alimentaçáo humana, com maiores teores de proteínas, menores valores de gorduras trans e altos teores de ácido oleicos, com o objetivo de diversificar a produção e conseguir se manter no mercado altamente concorrido. Estes materiais de soja ja estáo sendo plantados comercialmente nos Estados Unidos (VistiveGold'), estando em fase de tramitação na CTNBio para liberação para o mercado brasileiro.

\section{REFERÊNCIAS}

BRASIL, Ministério da Agricultura Pecuária e Abastecimento. Balanços de oferta demanda Brasil. Brasília, 2015. Disponível em: < http://www.agricultura.gov.br/ vegetal/estatisticas >. Acesso em: 13 abr. 2016.

BRASIL, Ministério da Agricultura Pecuária e Abastecimento. Portaria MAPA no 437 de 21/10/2005. Reconhece as localidades, os municípios e as Unidades da Federação, que especifica, como zonas de exclusão nas quais não poderão ser cultivados sementes ou caroços de algodão (Gossypium hirsutum) com traços de eventos de transformação genética.Disponível em: < https://www.legisweb. com.br/legislacao/?id=192975>. Acesso em: 15 abr. 2016.

BORÉM,A.; FRITSCHE-NETO, R. Biotechnology and

Plant Breeding: Applications and Approaches for Developing Improved Cultivars. 1st ed. [S.1.]: Academic Press, 2014, 272p. 
BORTOLI, S. A. et al. Herbivoria em soja: Efeito na composição química das folhas e na biologia da lagarta da soja e do percevejo verde pequeno. Comunicata Scientiae, v. 3, n. 3, p. 192-198, 2012.

CARRER, H.; BARBOSA, A. L.; RAMIRO, D. A. Biotecnologia na agricultura. Estudos avançados, v.24, n.70, 2010 .

CENTRO DE ESTUDOS AVANÇADOS EM ECONOMIA APLICADA. PIB Agro CEPEA-USP/CNA, PIB do Agronegócio - Dados de 1995 a 2015. São Paulo: CEPEA, 2014. Disponivel em: < http://cepea.esalq.usp.br/ pib/ />. Acesso em: 13 abr. 2016.

COMPANHIA NACIONAL DE ABASTECIMENTO. Acompamento da safra brasileira de gráos., Brasília, 2014. v.1 - Safra 2013/14, n.11 - Décimo Primeiro Levantamento Disponível em < http://www.conab.gov.br/OlalaCMS/uploads/arquivos/14_08_07_08_59_54_boletim_ graos_agosto_2014.pdf>. Acesso em: 02 de fev. de 2016.

JAMES, C. Status Global das Cultivares Transgênicas Comercializadas: 2014. 34p. Relatório N. 49.

LANDGRAF, L. Pragas mais resistentes a químicos exigem mudança nas estratégias de controle Embrapa Soja. 2014. Disponível em: < https:/www.embrapa. br/busca-de-noticias/-/noticia/2334543/pragas-mais-resistentes-a-quimicos-exigem-mudanca-nas-estrategias-de-controle>. Acesso em 13 abr. 2016.

MENEGATTI, A. L. A.; BARROS, A. L. M. Análise comparativa dos custos de produção entre soja transgênica e convencional: um estudo de caso para o Estado do Mato Grosso do Sul. Rev. Econ. Sociol. Rural v.45, n.1, 2007

MENEGHINI R., PACKER, A.L. Articles with authors affiliated to Brazilian institutions published from 1994 to 2003 with 100 or more citations: II: identification of thematic nuclei of excellence in Brazilian science. An. Acad. Bras. Ciênc., v.78, n.4, p. 855-883, 2006.

MOSCARDI, F. et al. Artrópodes que atacam as folhas da soja. In: HOFFMANN-CAMPO, C.B.; CORREA-FERREIRA, B.S.; MOSCARDI, F. (Ed.). Soja: manejo integrado de insetos e outros artrópodes-praga. Brasília: Embrapa, 2012. p. 211-334.

ORGANIZAÇÓES DAS NAÇÓES UNIDAS. ONU projeta que populaçáo mundial chegue aos $8,5 \mathrm{mil}$ milhóes em 2030, 30 de julho de 2015. Disponível em: http://www.unric.org/pt/actualidade/31919-onu-projeta-que-populacao-mundial-chegue-aos-85-mil-milhoes-em-2030. Acesso em: 13 abr. 2016.
SOUZA, F.J.V. et al. Perfil Dos Artigos Sobre Agronegócio Publicados Nos Periódicos De Contabilidade Com Estrato Capes. ConTexto, v. 12, n. 22, p. 87-102, 2012. 